\title{
CSF Monoamine Metabolites and Somatostatin in Alzheimer's Disease and Major Depression
}

\author{
Susan E. Molchan, Brian A. Lawlor, James L. Hill, \\ Rick A. Martinez, Candace L. Davis, Alan M. Mellow, \\ David R. Rubinow, and Trey Sunderland
}

Decreased cerebrospinal fluid (CSF), somatostatinlike immunoreactivity (SLI) and alterations in the CSF monamine metabolites 3-methoxy-4-hydroxyphenylethylglycol (MHPG), 5-hydroxyindoleacetic acid (5-HIAA), and homovanillic acid (HVA) have been reported in patients with probable Alzheimer's disease (AD) and in patients with major depression. In this study, we found CSF SUI to be significantly lower in a large group of AD patients (n $=60)$ and in a group of age-matched patients with major depression $(\mathrm{n}=18)$ as compared with normal controls $(\mathrm{n}=12)$. Mean CSF, MHPG, 5-HIAA, and HVA levels were not significantly different among diagnostic groups. Within a group of "depressed" $A D$ patients, CSF levels of 5-HIAA showed a significant positive correlation ( $\mathrm{p}=0.03$ ) with CSF SLI; a similar relationship was found within the group of patients with major depression. Further exploration of the relationship between the somatostatin and serotonin systems may provide clues as to how neuropeptides interact with monoamine neurotransmitters and what role they have in depression.

\section{Introduction}

Decreased somatostatinlike immunoreactivity (SLI) has been a consistent finding in many studies of the cerebrospinal fluid (CSF) and brains of patients with Alzheimer's disease (AD) (Davies et al 1980; Francis et al 1984; Sunderland et al 1987; Davis et al 1988), as well as in the CSF of patients with major depression (Rubinow et al 1983; Bissette et al 1986). In normal brain the highest concentrations of the tetradecapeptide, somatostatin, exist in the hypothalamus and limbic system, including the amygdala and hippocampus, those areas of the brain thought to be especially involved in affective and cognitive functions. In the central nervous system (CNS), somatostatin functions as a neuromodulator, if not a neurotransmitter (Rubinow et al 1983). CSF SLI is thought to reflect brain SLI as reviewed by Rubinow (1986).

From the Unit on Geriatric Psychopharmacology, Laboratory of Clinical Science, National Institute of Mental Health, Bethesda, MD (SEM, JLH, RAM, TS); Division of Geropsychiatry, Department of Psychiaty, Mount Sinai School of Medicine, New York, NY (BAL); Department of Psychiatry, University of Michigan iviedical Center, Ann Arbor, MI (AMM); Section on Behtavioral Endocrinology, Biological Psyciniairy Biäucii, Sivational Institute of Mental Health, Bethesda, MD (CLD, RRR).

Address reprint requests to Dr. Susan E. Molchan, Unit on Geriatric Psychopharmacology, Laboratory of Clinical Science, National Institute of Mental Health, NIH Clinical Center, 10-3D41, 9000 Rockville Pike, Bethesda, MD 20892.

Recı:ived August 22, 1990; revised November 17, 1990. 
Many interactions between somatostatin and the monoamine neurotransmitters have been documented (see Rubinow 1986 for review). While most discussions of AD focus on the cholinergic system deficits (Davies and Maloney 1976; Whitehouse et al 1982), alterations have been reported in other neurotransmitter systems (Gottfries 1985), especially the noradrenergic (Bondareff et al 1982; Zweig et al 1988) and serotonergic systems (Mann and Yates 1982; Cross et al 1984; Crow et al 1984; Yamamoto and Hirano 1985; Baker and Reynolds 1989; Sparks 1989); the data have been less consistent for the dopaminergic system (Soirinen et al 1981; Gottfries 1985). Alterations in these monoamine neurotransmitter systems have also been documented in the brains and CSF of patients with major depression (Asberg et al 1984; Roy et al 1985; Mann et al 1986; Yates et al 1990), and the monoaminergic theory remains one of the prime etiological theories of depression (Rothschild 1988).

Depressed mood is increasingly recognized to be an important symptom in AD patients; most studies estimate that from $17 \%$ to $50 \%$ of these patients have significant depression at some time during the course of the disease (Reding et al 1985; Reifler et al 1986). AD patients with major depression have been found to have significantly more degeneration in the locus ceruleus and substantia nigra than nondepressed AD patients (Zubenko and Moossy 1988). Similar findings in the locus ceruleus were found in another study (Zweig et al 1988), which also found that AD patients with major depression had significantly fewer neurons in the central superior (raphe) nucleus, and a trend for such a loss in the dorsal raphe nucleus. Zubenko and coworkers (1990) recently reported that demented patients with major depression had a ten-fold decrease of cortical norepinephrine, an increase in dopamine levels in entorhinal cortex, and a decrease in serotonin that approached significance in frontal cortex.

Studies in animals have shown that somatostatin affects many behavioral functions, including sleep, appetite, circadian rhythm, motor activity, and pain sensitivity (functions that are commonly disrupted in depression) (Reichlin 1982; Rubinow et al 1983). Because of the overlapping cognitive and behavioral symptoms and abnormal biological measures in $\mathrm{AD}$ and major depression and earlier work showing alterations in CSF SLI and monoamine levels in both AD and elderly depression (Sunderland et al 1987; Davis et al 1988), we sought to determine the relationship between CSF SLI, CSF monoamines, measures of depression, and measures of dementia severity in these populations.

\section{Methods}

\section{Subjects}

Sixty patients with $\mathrm{AD}$ (mean $\pm \mathrm{SD}$ age $=66.2 \pm 8.7$ years; 32 wornen, 28 men), 18 patients with major depression ( $64.6 \pm 9.9$ years; 12 women, 6 men), and 12 normal controls (65.8 \pm 10.7 years; 4 women and 8 men) were included in the study. All patients and controls were studied as inpatients at the National institute of Mental Health (NIMH). Primary degenerative dementia of the Alzheimer type and major depression were diagnosed according to DSM-III-R criteria (American Psychiatric Association 1987). Some $\mathrm{AD}$ patients had significant depressive symptoms and may have had a prior history of depression. Symptoms of depression in these patients were considered a secondary phenomenon, with dementia being the primary diagnosis. Patients with serious medical problems were excluded from the study. Normal controls were screened to exclude those with a personal or family history of any significant medical, cognitive, or psychiatric 
disorder. Normal controls were recruited from the community and were paid for their participation. All subjects were free of centrally active drugs for at least 3 weeks before the study. All subjects gave written informed consent. For AD patients, a relative also signed the consent form.

\section{Rating Scales}

Patients with AD were evaluated with the Dementia Mood Assessment Scale (DMAS) (Sunderland et al 1988a, 1988b), a 24-item scale in which the first 17 items are designed to measure depression in dementia (DMAS-17) and the last 7 items to measure cognitive and functional impairment. The DMAS-17 has some questions that are similar to those on the Hamilton Depression Scale (Hamilton 1960), but the two scales are not equivalent (Sunderland et al 1988a). AD patients were also evaluated with the modified BunneyHamburg Global Behavioral Rating Scales (Bunney and Hamburg 1963; Sunderland et al 1988a) to rate different aspects of behavior, mood, and impairment, with scores ranging from 0 (no impairment) to 13-15 (very severe). Patients diagnosed with major depression were rated with the Hamilton Depression Scale as well as the Bunney-Hamburg Global Behavioral Rating Scales. Dementia severity was rated using the Global Detericration Scale (GDS) (Reisberg et al 1982) and the Clinical Dementia Rating Scale (CDR) (Hughes et al 1982).

\section{CSF Measures}

Lumbar punctures (LPs) were done between 8:00-9:00 AM on subjects in the 'ateral decubitus position, after an overnight fast, and after at least 3 days on a low monoamine diet. Subjects were on bed-rest prior to the LP, except for voiding. The 26 th $\mathrm{ml}$ of collected CSF was immediately frozen without preservatives on dry ice and then stored at $-70^{\circ} \mathrm{C}$ for later measurement of SLI. The 10th through 15 th $\mathrm{mls}$ of each CSF sample were frozen at $-70^{\circ} \mathrm{C}$ and used to measure the neurotra-smitter metabolites 3-methoxy4-hydroxyphenylethylglycol (MHPG), 5-hydroxyindoleacetic acid (5-HIAA), and homovanillic acid (HVA) as described elsewhere (Scheinin et al 1983). All moncamines were assayed in the Laboratory of Clinical Science, NIMH. The SLI radioimmunoassay was done by the Section on Behavioral Endocrinology, NIMH and used 125I-tyrosine-1-somatostatin, rabbit antisomatostatin antiserum (kindly provided by Dr. Seymour Reichlin, Tufts University), synthetic cyclic somatostatin standards, and charcoal separation, and was performed using procedures described elsewhere (Patel et al 1977). Assay sensitivity is $1 \mathrm{pg} /$ tube, with an $\mathrm{ED}_{50}$ of $8.6 \mathrm{pg} /$ tube. The antisomatostatin antibody used is directed toward the midportion of the tetradecapeptide, so it recognizes $\mathrm{N}$-terminal extensions of somatostatin-14, such as somatostatin-28. Samples from AD, depressed, and normal subjects were run in the same assays. The intraassay coefficient of variation was about $6 \%$; the interassay coefficient of variation for this assay is $12 \%-15 \%$.

\section{Data Analysis}

CSF SLI and monoamine levels were compared between diagnostic groups by one-way ANOVA and post hoc Bonferroni $t$-tests. Pearson's product-moment correlations were used to explore potential relationships among measures of mood, dementia severity, CSF 
Table 1. Demographic and Clinical Data ${ }^{a}$

\begin{tabular}{lccc}
\hline \multicolumn{1}{c}{ Parameter } & $\begin{array}{c}\text { Alzheimer patients } \\
(n=60)\end{array}$ & $\begin{array}{c}\text { Depressed patients } \\
(n=18)\end{array}$ & $\begin{array}{c}\text { Normal controls } \\
(n=12)\end{array}$ \\
\hline Age (years) & $66.2 \pm 8.7$ & $64.6 \pm 9.9$ & $65.8 \pm 10.7$ \\
Gender & $32 \mathrm{~F}, 28 \mathrm{M}$ & $12 \mathrm{~F}, 6 \mathrm{M}$ & $4 \mathrm{~F}, 8 \mathrm{M}$ \\
Illness duration (years) & $3.8 \pm 2.6$ & & \\
Age of onset (years) & $62.2 \pm 9.0$ & & \\
Dementia severity & $4.5 \pm 1.0$ & & \\
$\quad$ Global Deterioration Scale & $1.7 \pm 0.6$ & & \\
$\quad$ Clinical Dementia Rating Scale & & & \\
Dementia Mood Assessment Scale & $23.0 \pm 9.9$ & & \\
$\quad$ 17-item & & $22.4 \pm 7.1$ & \\
Hamilion Depression Scale & & $30.0 \pm 8.6$ & \\
$\quad$ 17-item & & $6.9 \pm 2.1$ & \\
$\quad$ 24-item & $4.3 \pm 1.8$ & $1.9 \pm 2.2$ & \\
Bunney-Hamburg Global Scales & $5.2 \pm 2.2$ & $6.6 \pm 1.4$ & \\
$\quad$ Depression & $4.8 \pm 1.6$ & \\
Sadness & & \\
$\quad$ Anxiety & &
\end{tabular}

Values are mean \pm SD.

Not all patients had all ratings.

monoamine metabolites, and CSF SLI. To explore the relationship between CSF SLI and CSF monoamines in $A D$ patients with affective symptoms, the $A D$ group was divided a priori into "depressed" and "nondepressed," and "anxious" and "nonanxious" groups based on scores from the DMAS-17 and the Global Depression and Global Anxiety Scales. The scores differentiating "depressed" and "nondepressed" patients were based on the mean scores of those scales in a prior publication which established the validity of the use of those scales in AD patients (Sunderland, et al 1988a). Patients with scores greater than or equal to the mean in that prior study (scores of $\geq 25$ on the DMAS-17 and $\geq 5$ on the Global Depression and Anxiety Scales) were considered to have significantly more depressive or anxious symptoms than those with scores that were less than the mean. Data are presented as the mean \pm SD.

\section{Results}

Demographic and clinical characteristics of the subjects are summarized in Table 1. The CSF SLI levels of 60 patients with probable $\mathrm{AD}$ and the group of 18 elderly depressives was decreased significantly from that of the age-matched controls (df $=2,87, F=$ $11.42, p<0.001$ ) (see Table 2). CSF SLI levels differed significantly between the "depressed" and "nondepressed" AD patients (Table 2). CSF 5-HIAA did not differ significantly between diagnostic groups ( $\mathrm{df}=2,85, F=2.41, p<0.10$ ) (Table 2), nor did CSF MHPG or HVA levels (df $=2,84, F=2.24, p<0.11$ and $\mathrm{df}=2,85$, $F=0.14, p<0.87$, respectively) (Table 2). The CSF 5-HIAA levels among the major depression patients, the "depressed" $A D$ patients and the "nondepressed" $A D$ patients did not differ significantly (df $=2,59, F=2.353, p<0.20$ ) (Table 2). Mean CSF MHPG and HVA levels also did not differ significantly among these 3 groups 'df = $2,59, F=2.35, p<0.10$ and $\mathrm{df}=2,59, F=2.28, p<0.11$, respectively).

In the overall group of $\mathrm{AI}$ ) patients, there was no significant concliation between any 
Table 2. Mean Levels ( \pm SD) of CSF Somatostatinlike Immunoreactivity and CSF Monoamine Metabolites

\begin{tabular}{lllccc}
\hline Group $(n)$ & & \multicolumn{1}{c}{$\begin{array}{c}\text { SLI } \\
(\mathrm{pg} / \mathrm{ml})\end{array}$} & $\begin{array}{c}\text { 5-HIAA } \\
(\mathrm{pmol} / \mathrm{ml})\end{array}$ & $\begin{array}{c}\text { MHPG } \\
(\mathrm{pmol} / \mathrm{ml})\end{array}$ & $\begin{array}{c}\text { HVA } \\
(\mathrm{pmol} / \mathrm{ml})\end{array}$ \\
\hline Alzheimer's & $(60)$ & $37.2 \pm 15.5^{a}$ & $93.0 \pm 30.9$ & $51.3 \pm 16.0$ & $187.9 \pm 74.1$ \\
"Depressed" & $(18)^{*}$ & $32.4 \pm 15.5^{b}$ & $92.0 \pm 36.0$ & $50.1 \pm 14.6$ & $166.3 \pm 65.8$ \\
"Nondepressed" & $(26)^{*}$ & $42.0 \pm 15.6$ & $100.2 \pm 28.5$ & $50.3 \pm 16.4$ & $213.7 \pm 69.0$ \\
Major Depression & $(18)$ & $45.1 \pm 15.5^{a, c}$ & $112.1 \pm 37.0$ & $60.8 \pm 20.9$ & $190.2 \pm 83.5$ \\
Controls & $(12)$ & $60.2 \pm 16.1$ & $94.5 \pm 34.3$ & $51.1 \pm 14.7$ & $201.6 \pm 66.4$ \\
\hline
\end{tabular}

Different from controls, $p<0.001$.

'Different from "nondepressed" $\mathrm{AD}$ patients, $p<0.03$.

"Different from "depressed" AD patients, $p<0.01$.

*44/60 AD patients were evaluated with depression ratings.

of the CSF monoamine metabolites and SLI. When the AD group was divided into "depressed" and "nondepressed" 5-HIAA was the only metabolite to correlate significantly with SLI in the group of "depressed" AD patients as well as in the group of patients with major depression $(r=0.49, p<0.03, n=20$ and $r=0.55, p<0.02, n=18$, respectively) (Figures 1 and 2). A similar relationship was found between SLI and 5HIAA ( $r=0.40, p<0.04, n=26$ ) (and not MHPG and HVA) in the group of "anxious" $\mathrm{AD}$ patients, and also in "anxious" patients with major depression $(r=0.54, p<0.04$, $n=12$ ). Neither CSF SLI nor 5-HIAA correlated with measures of dementia severity.

\section{Comment}

In our study, a significant positive relationship between CSF SLI and CSF 5-HIAA was found within a group of depressed $A D$ patients and within a group of patients with major depression; this relationship was consistent across the different scales used to assess mood. The other monoamine metabolites examined, MHPG and HVA, showed no such relationship with SLI. These results suggest an interaction between serotonin and so-

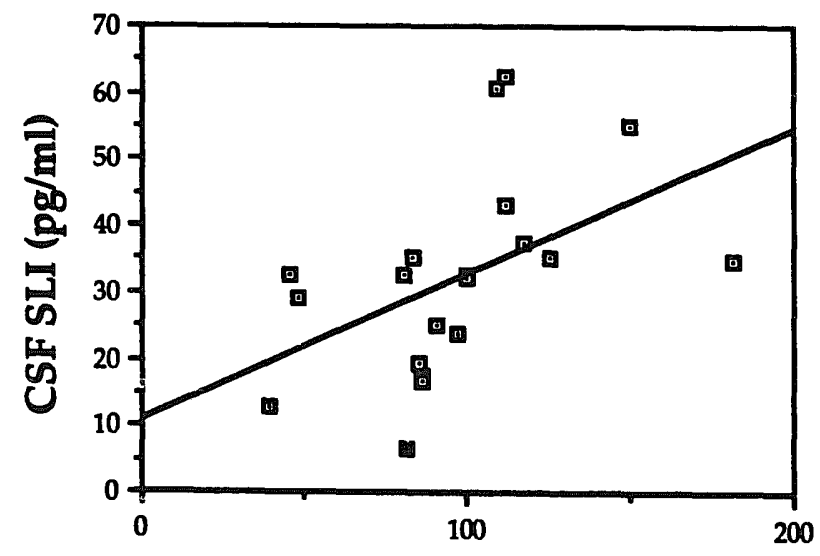

Figure 1. Correlation between CSF SLI and CSF 5-HIAA in "depressed" $\mathrm{AD}$ patients $(r=0.49 ; p<0.03 ; n=20)$. 


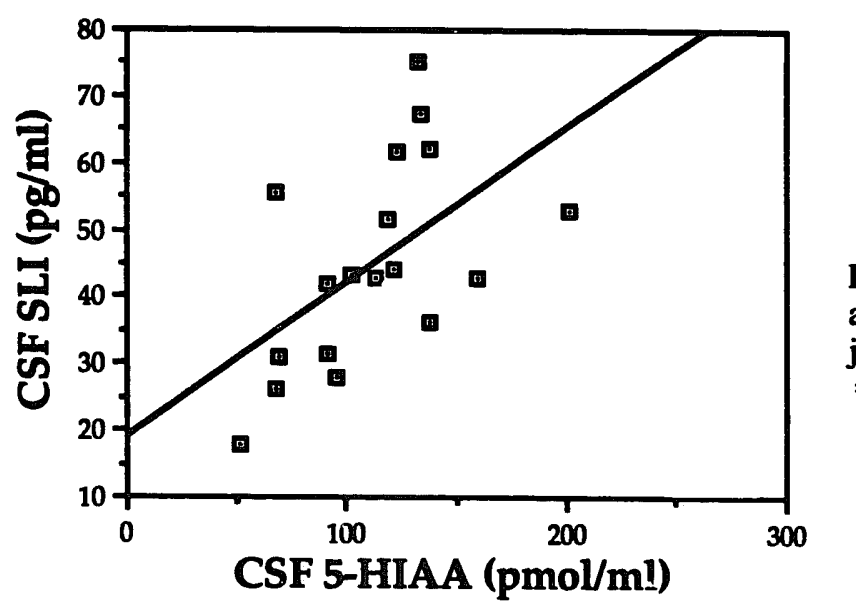

Figure 2. Correlation between CSF SLI and CSF 5-HIAA in patients with major depression $(r=0.55 ; p<0.22 ; n$ = 18).

matostatin related to depressed and anxious mood in both these patient groups. The finding of this relationship on rating scales designed to measure depressed mood (the DMAS 17item and the Global Depression Scale) and anxiety (Globall Anxiety Scale) is consistent with the frequent coexistence of these symproms in patients with major depression, especially in the elderly (Salzman 1990).

Prior studies of the CSF and brains of $\mathrm{AD}$ patients have also suggested a relationship between serotonin and somatostatin, though in none of these studies was depressed mood or the presence of major depression evaluated. In one study, decreased numbers of serotonin receptors correlated with decreased SL.I concentrations in the cortices of AD patients (Beal et al 1985). A significant correlation between decreased 5- $\mathrm{HT}_{2}$ (serotonin) receptor binding and SLI in temporal and frontal cortices of $\mathrm{AD}$ patients has also been reported (Cross et al 1984). In another study, decreased CSFF SLI concentrations in AD patients paralleled decreased CSF 5-HIAA and HVA concentrations (Francis et al 1984).

In depressed patients, the relationship between decreased SLI levels and CSF monoamines has been inconsistent. In a study of patients with major depression, Rubinow and coworkers found a significant positive correlation between CSF SLI and CSF 5-HIAA in seven patients, a positive correlation with MHPG in a small number of patients, and a significant negative correlation between SLI and norepinephrine in 16 patients (Rubinow et al 1983). In a previous study, we found no such relationship in 20 older patients diagnosed with major depression (Sunderland et al 1987). In a study of 85 patients with major depression, Agren and Lundqvist found that SLI correlated negatively with MHPG/HVA (Agren and Lundqvist 1984). Bissette er al (1986) found no correlation between CSF SLI and monoamines in 29 patients with major depression. Small numbers of subjects, different diagnostic criteria, different symptom and demographic profiles, different rating scales, and different assay methods may have contributed to these different findings and the lack of a clear relationship between CSF monoamines and CSF SLI.

In $\mathrm{AD}$, loss of $5-\mathrm{HT}_{2}$ receptors may be an early change in the pathological process (Cross et al 1984). Studies of SLI indicate that changes in the somatostatin system also appear to occur early (Roberts et al 1985; Nakamura and Vincent 1986). Our data support that changes in these systems occur early, in that neither SLI or 5-HIAA correlated with age, dementia severity, or duration of dementia symptoms. Depression can occur early 
in the course of $\mathrm{AD}$ and can even be an initial symptom (Reding et al 1985; Reifler et al 1986). Whether there is a relationship between early depressive symptoms (some of our "depressed" patients were not just beginning the course of their illness) and deficits in the somatostatin and/or serotonin systems is open for future studies. The study of cortical somatostatin and $5-\mathrm{HT}_{2}$ receptors may also provide clues as to which neurons are susceptible to the pathological pracesses in AD and why, in that both are thought to be located predominantly on intrinsic neurons. The primary damage in these systems is thought to be in the terminal fields, especially in the temporal cortex and hippocampus, areas of the brain that are known to be affected early in AD (Cross et al 1984; Roberts et al 1985; Nakamura and Vincent 1986). Further studies of the relationship between the somatostatin and serotonin systems may provide clues as to how neuropeptides interact with monoamine neurotransmitters and what role those interactions have in AD and in depression.

\section{References}

Agren H, Lundqvist G (1984): Low levels of somatostatin in human CSF mark depressive episodes. Psychoneuroendocrinology 9:233-248.

American Psychiatric Association (1987): Diagnostic and Statistical Manual of Mental Disorders, 3rd ed rev. Washington, DC: American Psychiatric Association.

Asberg M, Bertilsson L, Martensson B, et al (1984): CSF monoamine metabolites in melancholia. Acta Psychiatr Scand 69:201-219.

Baker GB, Reynolds GP (1989): Biogenic amines and their metabolites in Alzheimer's disease: Noradrenaline, 5-hydroxytryptamine and 5-hydroxyindole-3-acetic acid depleted in hippocampus but not in substantia innominata. Neurosci Lett 100:335-339.

Beal MF, Mazurek MF, Tran VT, et al (1985): Reduced numbers of somatostatin receptors in the cerebral cortex in Alzheimer's disease. Science 229:289-291.

Bissette G, Winderlov E, Walleus H, et al (1986): Alterations in cerebrospinai fiuid concentrations of somatostatin-like immunoreactivity in neuropsychiatric disorders. Arch Gen Fsychiatry 43:11481151.

Bondareff W, Mountjoy CQ, Roth M (1982): Loss of neurons of origin of the adrenergic projection to the cerebral cortex (nucleus locus coeruleus) in senile dementia. Neurology 32:164-168.

Bunney WE, Hamburg DA (1963): Methods for reliable longitudinal observation of behavior. Arch Gen Psychiatry 9:280-294.

Cross AJ, Crow TJ, Ferrier IN, et al (1984): Serotonin receptor changes in dementia of the Aizheimer type. J Neurochem 43:1574-1581.

Crow TJ, Cross AJ, Cooper SJ, et al (1984): Neurotransmitter receptors and monoamine metabolites in the brains of patients with Alzheimer-type dementia and depression, and suicides. Neuropharmacology 23:1561-1569.

Davies P, Maloney AJR (1976): Selective loss of ceniral cholinergic neurons in Alzheimer's disease. Lancet ii:1403-1405.

Davies P, Katzman R, Terry RD (1980): Reduced somatostatin-like immunoreactivity in cerebral cortex from cases of Alzheimer disease and Alzheimer senile dementia. Nature 288:279-280.

Davis KL, Davidson M, Yang RK, et al (1988): CSF somatostatin in Alzheimer's disease, depressed patients, and control subjects. Biol Psychiatry 24:710-712.

Francis PT, Bowen DM, Neary D, et al (1984): Somatostatin-like immunoreactivity in lumbar cerebrospinal fluid from neurohistologically examined demented patients. Neurobiol Aging 5:183186.

Gottfries CG (1985): Alzheimer's disease and senile dementia: Biochemical characteristics and aspects of treatment. Psychopharmacology 86:245-252. 
Hamilton M (1960): A rating scale for depression. J Neurol Neurosurg Psychiatry 23:56-62.

Hughes CP, Berg L, Danziger WL, Coben LA, Martin RL (1982): A new clinical scale for the staging of dementia. Br J Psychiatry 140:566-572.

Mann DMA, Yates PO (1982): Serotonin nerve cells in Alzheimer's disease. J Neurol Neurosurg Psychiatry 43:113-119.

Mann JJ, Stanley M, McBride PA (1986): Increased serotonin-2 and beta-adrenerzic receptor binding in the frontal cortices of suicide victims. Arch Gen Psychiatry 43:954-959.

Nakamura S, Vincent SR (1986): Somatostatin- and Neuropeptide Y-immunoreactive neurons in the neocortex in senile dementia of Alzheimer's type. Brain Res 370:11-20.

Patel Y, Rao K, Reichlin S (1977): Somatostatin in human cerebrospinal fluid. $N$ Engl $J$ Med 296:529-533.

Reding M, Haycox J, Blass J (1985): Depressi i in patients referred to a dementia clinic: A threeyear prospective study. Arch Neurol 42:894-896.

Reichlin S (1982): Somatostatin in the nervous system. In Bloom FE, Bird S, Schmitt FO (eds), Molecular Genetic Neuroscience. New York: Raven Press, pp 359-372.

Reifler BV, Larson E, Teri L, et al (1986): Dementia of the Alzheimer's type and depression. $J$ Am Geriatr Soc 34:855-859.

Reisberg B, Ferris SH, de Leon MJ, et al (1982): The Global Deterioration Scale for assessment of primary degenerative dementia. Am J Psychiatry 139:1136-1139.

Roberts GW, Crow TJ, Polak JM (1985): Location of neuronal tangles in somatostatin neurones in Alzheimer's disease. Nature 314:92-94.

Rothschild AJ (1988): Biology of depression. Med Clin of North Am 72:765-790.

Roy A, Pickar D, Linnoila M, et al (1985): Cerebrospinal fluid monoamine and monoamine metabolite concentrations in melancholia. Psychiatry Res 15:281-292.

Rubinow DR (1986): Cerebrospinal fluid somatostatin and psychiatric illness. Biol Psychiotry 21:341-365.

Rubinow DR, Gold PW, Post RM, et al (1983): CSF somatostatin in affective illness. Arch Gen Psychiatry 40:409-412.

Salzman C (1990): Practical considerations in the pharmacologic treatment of depression and anxiety in the elderly. J Clin Psychiatry 51(Suppl 1):40-43.

Scheinin M, Chang W-H, Kirk KL, et al (1983): Simultaneous determination of 3-methoxy-4hydroxyphenylglycol, 5-hydroxyindoleacetic acid and homovanillic acid in cerebrospinal fluid with high performance liquid chromatography using electrochemical detection. Anal Biochem 131:246-253.

Soininen H, MacDonald E, Rekonen M, et al (1981): Homovanillic acid and 5-hydroxyindoleacetic acid in cerebrospinal fluid in patients with senile dementia of the Alzheimer type. Acta Neurol Scand 64:101-107.

Sparks DL (1989): Aging and Alzheimer's disease. Arct Neurol 46:138-140.

Sunderland T, Rubinow DR, Tariot PN, et al (1987): CSF somatostatin in patients with Alzheimer's disease, older depressed patients, and age-matched control subjects. Am J Psychiairy 144:13131316.

Sunderland T, Alterman IS, Yount D, et al (1988a): A new scale for the assessment of depressed mood in demented patients. Am J Psychiatry 145:955-959.

Sunderland T, Hill JL, Lawlor BA, et al (1988b): NIMH Dementia Mood Assessment Scale (DMAS). Psychopharmacol Bull 24:747-753.

Whitehouse PJ, Price DL, Struble RG, et al (1982): Alzheimer's disease and senile dementia: Loss of neurons in the basal forebrain. Science 215:1237-1239.

Yamamoto T, Hirano A (1985): Nucleus raphe dorsalis in Alzheimer's disease: Neurofibrillary tangles and loss of large neurons. Ann Neurol 17:573-577.

Yates M, Leake A, Candy JM, et al (1990): 5HT2 Receptor changes in major depression. Biol Psychiatry 27:489-496. 
Zubenko GS, Moossy J (1988): Major depression in primary dementia: Clinical and neuropathologic correlates. Arch Neurol 45:1182-1186.

Zubenko GS, Moossy J, Koop U (1990): Neurochemical correlates of major depression in primary dementia. Arch Neurol 47:209-214.

Zweig RM, Ross CA, Hedreen JC, et al (1988): The neuropathology of aminergic nuclei in Alzheimer's disease. Ann Neurol 24:233-242. 